\title{
Superhero Meets Princess: New Commercial Opportunities Obtained by Walt Disney's Acquisition of Marvel
}

\author{
Tianxuan $\mathrm{Wu}^{1, *}$ \\ ${ }^{1}$ School of Social Science, University of California Irvine, 92697, Irvine, CA, USA \\ *Corresponding author. Email: tianxuaw@uci.edu
}

\begin{abstract}
The value of the culture and entertainment industry has become increasingly demanding, competition among enterprises has become more intense. As one of the oldest entertainment companies, Disney has expanded its business footprint by acquiring content companies such as Marvel. This article uses Marvel as a typical acquisition target and analyzes whether the decision of merger and acquisition is sufficient for Disney's development. The article first introduced the basic situation of Disney and Marvel's companies and analyzed the impact of Disney's frequent mergers and acquisitions from the perspective of economic and industrial content. The author uses the SWOT model to study the opportunities and challenges that Disney will encounter in its future development. The research ideas and framework of this article hope to have great reference value for the development methods of the cultural and entertainment industry in the future.
\end{abstract}

Keywords: Walt Disney, Marvel Studio, Entertainment Industry, SWOT analysis.

\section{INTRODUCTION}

With the rapid economic development, enterprises are also facing various challenges [1, 2]. Corporate mergers and acquisitions have now become a major trend in corporate development. The acquisition is a way for companies to expand their own scale. Of course, not all corporate mergers and acquisitions will bring positive significance to the company.

Companies can supplement and adjust their assets through mergers and acquisitions to achieve the best profit scale and reduce their production costs [3]. Also, mergers and acquisitions enable companies to concentrate on single-variety production in one factory while maintaining the overall product structure. To reach the level of specialization, mergers and acquisitions can also solve a series of problems brought about by specialized production so that the various production processes can be organically coordinated to produce economies of scale.

Through mergers and acquisitions of different companies, companies can conduct specialized products and services for different customers or markets to meet the needs of different consumers; the expansion of the company's scale makes it relatively easy for companies to finance.

Mergers and acquisitions can bring market dominance effects to enterprises. Through the associated enterprises, enterprises can effectively control the activities of competitors and increase the barriers to entry and the differentiated advantages of the enterprises in their fields [4].

This paper is about Disney's acquisition of Marvel studio. After analyzing the details and influences of this acquisition, the conclusion is that, towards the entertainment industry, the diversity of cultural properties is necessary [5-7]. To seize a larger part of the market, the companies should try to satisfy the people's cultural and artistic preferences and gain long-term value. Flexible use of properties in different areas is a good way to push the popularity of characters in the global market. As creators who can influence human culture, the companies should follow the social expectations and moral requirements.

The objective of this study is to demonstrate acquisition is a proper choice for the content industry to improve the necessary base of its creation. However, after purchasing enough resources, the companies still need to analyze the social and cultural situation and 
combine different business segments to maximize profits and occupy the market. This paper focuses on the acquisition of Marvel by Walt Disney. Walt Disney recognizes acquisition as a method for maintaining its leading position in the entertainment industry. Readers are expected to learn about the effect of the acquisition on finance and content. Also, the writer will provide evaluation and recommendations for the cooperation of content companies.

The remainder of this article is organized as follows. Section 2 describes the firm information of Walt Disney and Marvel. Section 3 investigates the impact of the acquisition. Section 4 present the future analysis and give a SWOT analysis to this company. Section 5 summarizes the conclusion.

\section{FIRM DESCRIPTION}

Walt Disney shows a positive financial performance every year. Its revenue peaked at over $\$ 45 B$ in 2013. In March 2011, Walt Disney was named \#1 in entertainment on the world's most admired companies by Fortune. According to the research, Disney mainly operates in five business segments, the first is Media Networks, the second is Parks and Resorts, and the third is Studio Entertainment; the fourth one is Consumer Products, and the last one is Interactive. Although Walt Disney has its own great number of characteristics or other resources to produce movies, it still works to purchase more entertainment cultural companies to broaden the range of content. For example, in December 2009, Disney bought Marvel for $\$ 4$ billion.

Marvel was a little comic company at the beginning, and it faced risks of bankruptcy several times in history. However, Hollywood paid for the use of Marvel's properties provided an alternative revenue stream to support the company's tentative rebirth (Johnson, 2012). Marvel Studios relied on its comic books properties and then achieved huge economic growth. Its proprietary library has over 4,700 characters. The properties enabled Marvel to enter other industries like video games, filmmaking, and so on. After ensuring the big success of bringing comics to the big screen, Marvel made another amazing decision - setting up a "Marvel Cinematic Universe". It connected all the superheroes' individual films and built a larger, cohesive work. This brilliant action helped improve Marvel's reputation because all the characteristics represented one brand, and it highlighted the special advantage that Marvel has so many original resources to create movies.

\section{INFLUENCE OF THE ACQUISITION}

Scalar variables and physical constants should be italicized, and a bold (non-italics) font should be used for vectors and matrices. Do not italicize subscripts unless they are variables. Equations should be either display (with a number in parentheses) or inline. Use the built-in Equation Editor or MathType to insert complex equations.

\subsection{To Finance}

Investing in Marvel's properties represents less risk since the "Marvel Universe" has guaranteed the popularity of its characteristics. Marvel studio's success not only gathered a large number of fans but also attracted the film capital. If the investors analyze other plans, they cannot be sure about the reaction of the market. However, towards Marvel, the comics help the films open the market at first. Although the content is unavailable before releasing the movies, the main characteristics can directly advocate the audience, thanks to the comics.

Besides studio entertainment, Marvel has increased the diversity and profits of all the other business segments in Disney. For example, Disney Parks and Resorts are famous around the world. Most facilities in the parks are designed based on particular stories. Before purchasing Marvel, the characteristics in parks were limited to animals and princesses, so the ideal customers were only targeted at children. While the joint of superheroes support the construction of more exciting and challenging projects. As a result of this, the Disney Parks have become good destinations for adults as well.

For better sales, the business segments should improve interaction and adjust supply accordingly, concluded from the first success of Marvel. The movie Spider-Man plays the hugest wave of interest in the comic market. Before the movie, the best record of sales of books was around 100,000 units. Then, the regular launch of comics often breaks 200,000 units. The synergy effect is very common in Disney or Marvel. However, towards the finance of the whole company, the effect can be hard to evaluate. Therefore, if Disney and Marvel can provide suitable works for the market, the success can be remarkable since the characters can produce profits in all the business segments. Contrarily, if the company invests in one project and it failed to make a huge influence, all the business segments will suffer huge pressure.

I collect the stock change data of Disney from yahoo finance from $1 / 12 / 2008$ to $1 / 12 / 2010$ (Figure 1). I analyze the acquisition's impact on this event. On December 31, 2009, Disney's acquisition of Marvel Entertainment was officially approved. The stock price trend chart shows that the public and investors are very appreciative of this acquisition from the process of the acquisition to the completion of the acquisition. From an expressive business look, the acquisition of Marvel has a huge improvement on the commercial value of Disney, which greatly enhances the company's competitiveness. 


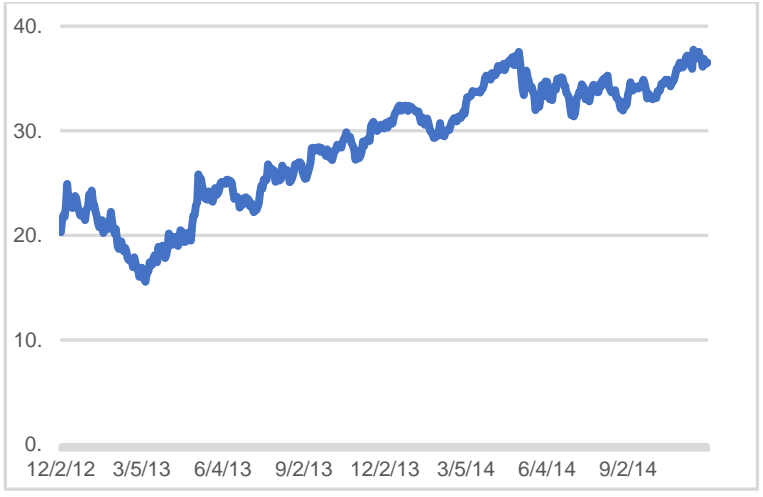

Figure 1. Disney's stock price between and after the acquisition

\subsection{To Content}

The combination of Marvel and Disney can inspire both to create something really new. In traditional opinions, Disney represents girls' childhood, while Marvel tends to be more attractive to boys. Also, compared to the superhero movies, which containing fight even violence, the productions of Disney tend to be more romantic and fairytale. Researchers analyzed the targeted audience of Marvel and Disney, and the conclusion is that although most of their works reflect a good performance in the market, the group of audience rarely overlap. Therefore, the adding of Marvel make up a large part of the whole market for Walt Disney.

Both Marvel and Disney succeeded in building up a specific brand reputation around the global market. However, sticking to one style is dangerous for an entertainment company since the audience may get bored with frequent similar stories. The audience is willing to see more hazardous elements in princess stories and more romantic clues in superheroes' risks. The new things cannot change the whole brand but make the structures of stories more complex in a good way. More people might accept their works, and the original audience can keep finding surprises in upcoming movies.

\section{FUTURE ANALYSIS}

The value of the entertainment industry keeps increasing in recent years. As a famous organization, Walt Disney gathered a large number of resources, and its "Entertainment - Diversified" category provides itself with a system of effective promotion everywhere around the world. In this part, readers will learn about the future development of Walt Disney after obtaining media brands, including Marvel. Besides the obvious advantages it has, Walt Disney faces challenges from competitors, the public, and so on. Investors might better understand the inner construction of the company before making a business decision about entertainment companies.

\subsection{SWOT Analysis}

A SWOT analysis is a technique for assessing strengths, weaknesses, opportunities, and threats, four aspects of one business $[8,9]$. While most widely used by organizations from small businesses and non-profits to large enterprises, a SWOT analysis can be used for both personal and professional purposes [10]. This part will discuss these four factors of Disney after purchasing Marvel studio.

\section{(1) Strengths}

This company owes a good reputation. Creativity, truth, innovation, optimism, and quality have been believed to be Walt Disney's symbols. The company is known for its persuasive entertainment proficiencies. The history in the diversion business is over 75 years. In the 1950s, Disney started to produce TV shows, such as Mickey Mouse club. The theme parks provided a totally new choice for people to carry out family entertainment. Much of the new technology used at the parks was cutting edge and led to widespread worldwide. Walt Disney created so many breakthroughs in history that its \#1 position in the industry is undeniable.

Then it also has abundant properties. Good stories are the basis for the creation of entertainment. Walt Disney's acquisitions include: Marvel, Lucas film, ABC, Pixar, and ESPN. All the companies have their own original properties. For example, Marvel owns over 4,700 characters in its comics. Compared to other competitors, Marvel saves much time looking and negotiating for the properties of good characters.

\section{(2) Weaknesses:}

The social expectation and criticism. Culture often bears the pressure of education. Disney is so famous that its production can affect so many people, especially for its biggest group of the audience-children and teenagers. Young people need to build a healthy and positive perspective towards life. Many people, like feminists, once assumed that the princess stories of Disney advocate a wrong direction for girls' future. According to this problem. Disney has already taken action in recent years. Many movies which have independent and brave female characters are brought to the big screen.

High costs of all the projects. We all know that superhero movies have a lot of special effects. The expense of making this dramatic use of CGI is extremely high.

\section{(3) Opportunities}

The market value of the entertainment industry is increasing year by year. People are increasingly willing to spend in the entertainment industry. Disney's theme parks worldwide can greatly promote the popularity of the role in the global market. In addition to offline theme 
parks, Disney is also continuously investing financial and human resources in technology. Disney has reached a partnership with Apple TV to design an exclusive channel for Disney, and Disney's own official application software has also entered the market. Disney should fully seize the offline and online business opportunities, construct a Disney World that combines the Internet and reality, and promote the coverage of its content in the global market.

\section{(4) Threats}

Disney is not sure about the quantity of "charming enough characters" that Marvel is owning. Since the beginning of Marvel's success, some professional analysts keep doubting the continuity of the popularity. Though series like Iron-Man, Spider-Man, and Captain America are proved to be profitable, it is still unknown for people that whether Marvel can find out more characteristics that have such huge potential in the market.

\subsection{Recommendation to Disney}

The company should spend more on selecting new characters. Both Marvel and Disney rely on the long-term value of the roles. As we talked about before, production is always a huge cost. Investors need "reliable" characters, so the company should predict the market's reaction and find out the correct ones from the thousands of characters in the comic books.

The process of finding correct characters, and serving as their talent agencies, can be challenging. First, the staff should find out the proper characters from the library. Some characters are getting famous once they are created, like Spider-Man. The sales of comic books guaranteed success in advance. While, sometimes, minor roles might get more attention. For example, the Black widow was just created for adding female elements, but she deeply attracted the audience. People assume her as a superhero without super-power and a rare female role who can fight with the male. The market always expects something new. Black Widow, appearing in the superhero movie, is a character out of people's imagination. In conclusion, the analysts should look for the characters capable of gathering quantities of fans without promotion on the big screen and the characters that are special enough. The second kind requires people to be familiar with all the existed roles in the industry.

Satisfying the development of culture and society can also help. Characters that are related to social symptoms will arouse an echo in the audience. The popularity of Black Widow can reflect the improvement of the position of women in society. People, especially female audiences, are willing to see a role like Black Widow have more abilities than beauty. Satisfying and support the social requirements can be a good direction for choosing the new superheroes and princesses.

\section{CONCLUSION}

In our analysis, readers are expected to know the influence of acquisition on Walt Disney and Walt Disney's financial statement. According to the above analysis, we find that the challenges in the development are inevitable for Walt Disney. The increased value of the industry has attracted many capitals and media companies to follow the steps of Disney. They are trying to take a share of Disney's profits. We also conduct a SWOT analysis of this company. According to the SWOT analysis, we can find that Walt Disney has a historical advantage in the market since its business movements are always in advance. Also, the most important thing for content companies _ original stories, thanks to the frequent acquisitions, Disney has a rich supply of which from the media companies like Marvel. Then, Walt Disney should keep an eye on the competitors' movements and keep the most creative energy to maintain the first position in the industry.

This article also has some limitations. The quantitative model used in this study is relatively small since relevant data is difficult to obtain. Future research plans can add more in-depth data analysis, investigating more reports and data sets for research.

\section{REFERENCES}

[1] Ingelsson, P., Eriksson, M., \& Lilja, J. (2012). Can selecting the right values help TQM implementation? A case study about organisational homogeneity at the Walt Disney Company. Total Quality Management \& Business Excellence, 23(1), 1-11.

[2] Rehman, M. (2021). Dream Bigger, Disney. Sustinere-The University of Toronto's Journal of Sustainable Development, 1(1), 113-130.

[3] Wasko, J. (2001). Challenging Disney Myths. Journal of Communication Inquiry, 25(3), 237-257.

[4] Bohas, A. (2015). Transnational firms and the knowledge structure: The case of the Walt Disney Company. Global Society, 29(1), 23-41.

[5] Wasko, J. (2016). The Walt Disney Company. In Global Media Giants (pp. 11-25). Routledge.

[6] Collis, D. J., \& Hartman, A. S. H. L. E. Y. (2017). Reawakening the magic: Bob Iger and the Walt Disney Company. Harvard Business School case, 717-483.

[7] Hill, T., \& Westbrook, R. (1997). SWOT analysis: it's time for a product recall. Long range planning, 30(1), 46-52.

[8] Helms, M. M., \& Nixon, J. (2010). Exploring SWOT analysis-where are we now? A review of 
academic research from the last decade. Journal of strategy and management.

[9] Phadermrod, B., Crowder, R. M., \& Wills, G. B. (2019). Importance-performance analysis based SWOT analysis. International Journal of Information Management, 44, 194-203.

[10] Balamuralikrishna, R., \& Dugger, J. C. (1995). SWOT Analysis--A Management Tool for Initiating New Programs in Vocational Schools. Journal of Vocational and Technical Education, 12(1), 36-41. 